\title{
SOLUBILITY OF ILAPRAZOLE IN VARIOUS ALCOHOLS IN TEMPERATURE RANGE BETWEEN (298.15 TO 322.15) K
}

\author{
Shipra BALUJA*, Kapil BHESANIYA \\ Physical Chemistry Laboratory, Department of Chemistry, \\ Saurashtra University, Rajkot-360005, India \\ *E-mail address: shipra_baluja@rediffmail.com
}

Keywords: Ilaprazole; alcohols; solubility; thermodynamic parameters

\begin{abstract}
The solubility of Ilaprazole in methanol, ethanol, 2-propanol and n-butanol was measured using a gravimetrical method at temperature ranging from $298.15 \mathrm{~K}$ to $322.15 \mathrm{~K}$. The results of these measurements were correlated with a semi empirical equation. Some thermodynamic parameters such as dissolution enthalpy, Gibb's free energy, and entropy of mixing have also been calculated.
\end{abstract}

\section{INTRODUCTION}

The production of pharmaceuticals involves solvent selection as a function of solubility, for formulation, purification and chemical reaction. Selection of optimum solvent for a particular application is important for developing efficient process. Further, solubility data is required for cost effective manufacturing processes.

Ilaprazole is a newly developed proton pump inhibitor ${ }^{1}$ for the treatment of dyspepsia, peptic ulcer disease, gastroesophageal reflux disease ${ }^{2}$ and duodenal ulcer. ${ }^{3,4}$ Literature survey shows that most of work reported for Ilaprazole is focused on the pharmacology, pharmacokinetics, metabolism, and quantitative determination. ${ }^{5-10}$ Due to these medicinal importance, it would be interesting to study the solubility of this drug in some solvents. The solubility data of this drug may be useful for its applications in other fields also.

Thus, in the present work, solubility of Ilaprazole is studied by a gravimetric method in some alcohols; methanol, ethanol, 2-propanol, and n-butanol over a temperature range $(298.15 \mathrm{~K}$ to $322.15 \mathrm{~K}$ ) at atmospheric pressure.

\section{RESULTS AND DISCUSSION:}

The mole fraction solubilities $x$ of Ilaprazole in methanol, ethanol, 2-propanol and n- butanol at different temperatures ( 298.15 to $322.15 \mathrm{~K}$ ) are presented in Table 1 and more visually given in Figure 2. It is observed that the solubility is minimum in n-butanol and maximum in methanol. Further, solubility increases nonlinearly with temperature.

The temperature dependence of Ilaprazole solubility in pure solvents was described by the modified empirical equation ${ }^{11,12}$ :

$$
\ln x=A+\frac{B}{T}+C \ln T
$$

where $T$ is the absolute temperature, and $\mathrm{A}, \mathrm{B}$, and $\mathrm{C}$ are empirical constants. The values of these parameters are listed in Table 2.

The root-mean-square deviations (RMSD) are calculated using the following equation:

$$
\mathrm{RMSD}=\sqrt{\sum_{i=1}^{N} \frac{\left(x_{i}-x\right)^{2}}{N-1}}
$$

where $N$ is the number of experimental points and $x$ and $x_{i}$ represent the mole fraction solubility of the experiment and that calculated from eq 1, respectively. These values are given in Table 2.

Further, relative deviations (RD) and relative average deviations (ARD) are calculated by eq (4) and (5) and are listed in Tables 1 and 2 respectively. 


$$
\begin{aligned}
R D & =\left(\frac{x-x_{i}}{x}\right) \\
\mathrm{ARD} & =\frac{1}{N} \sum_{i}^{N} \frac{\left(x-x_{i}\right)}{x}
\end{aligned}
$$

where $N$ is the number of experimental points and $x_{i}$ is the solubility calculated by eq 1 .

The dissolution of a substance in a solvent is associated with changes in thermodynamic parameters such as enthalpies of solution $\left(\Delta H_{s o l}\right)$, Gibb's energy of dissolution $\left(\Delta G_{s o l}\right)$ and entropy of solutions $\left(\Delta S_{\text {sol }}\right)$. The changes that occur in the solute during dissolution process can be explained by these thermodynamic functions. These parameters have also been evaluated from experimental solubility data.

The enthalpies of solution $\left(\Delta H_{s o l}\right)$ was calculated by modified van't Hoff equation ${ }^{13,14}$ i.e., from the slope of the plot of $\ln x$ versus $\left(1 / T-1 / T_{h m}\right)$.

$$
-\frac{\Delta H s o l}{R}=\frac{\partial \ln x}{\left(\frac{1}{T}-\frac{1}{T_{h m}}\right)}
$$

where $T$ is the experimental temperature and $\mathrm{R}$ is gas constant. $T_{h m}$ is the mean harmonic temperature which is given as

$$
T_{h m}=\frac{n}{\sum_{i}^{n}\left(\frac{1}{T}\right)}
$$

where $\mathrm{n}$ is the number of experimental temperatures ${ }^{15}$. In the present case, the $T_{h m}$ value obtained is only $309.97 \mathrm{~K}$. The slope of the plot of $\ln \mathrm{x}$ versus $(1 / T-1 / 309.97)$ gives the value of $\Delta H_{\text {sol }}$.

From the intercepts of these plots, Gibbs energy change $\left(\Delta G_{s o l}\right)$ for the solubility process were evaluated by the following relation ${ }^{13}$ :

$$
\Delta G_{\text {sol }}=-R T \text {. intercept }
$$

Using these evaluated $\Delta H_{s o l}$ and $\Delta G_{s o l}$ values, the entropies of solutions $\Delta S_{\text {sol }}$ were obtained from equation ${ }^{13,14}$

$$
\Delta S_{s o l}=\frac{\Delta H_{s o l}-\Delta G_{s o l}}{T_{h m}}
$$

All these thermodynamic parameters are given in Table 3. It is evident from Tables 3 that for the all the studied solvents, $\Delta H_{s o l}$ and $\Delta G_{s o l}$ values are positive whereas $\Delta S_{\text {sol }}$ values are negative, except for ethanol. When stronger bonds are broken and weaker bonds are formed, energy is consumed. So, $\Delta H_{\text {sol }}$ becomes positive. ${ }^{14}$ This indicates endothermic dissolution of drug. The positive value of $\Delta G_{\text {sol }}$ indicates spontaneous dissolution process. ${ }^{16}$ The negative value of entropy indicates increased order due to solvation process except for ethanol. The positive entropy in ethanol indicates favorable entropy of solubilization for drug in solution. On dissolution, randomness increases in studied solvents. Thus, higher positive $\Delta S_{\text {sol }}$ values suggest entropy-driving dissolution process.

\section{EXPERIMENTAL}

3.1. Materials Ilaprazole (CAS No. 172152-36-2), i.e., 2-[(4-Methoxy-3-methylpyridin-2yl)methylsulfinyl]-6-pyrrol-1-yl-1H-benzimidazole is white crystalline powder which was purchased from Hiran Orgochem Ltd. with mass fraction purity of 99.0\%.

All of the selected alcohols were of analytical grade and were purified by fractional distillation. The purity of solvents was checked by Shimadzu gas chromatography/mass spectrometry and were found to be greater than $99.5 \%$.

3.2. Solubility measurement: The gravimetric method was used to study the solubility. An excess mass of drug was added to a known mass of solvent. The solution was heated to a constant temperature with continuous stirring. The stirring was stopped after few hrs and the solution was allowed to approach equilibrium. This solution was then filtered and by a preheated injector, $2 \mathrm{ml}$ of this clear solution was taken in another weighted measuring vial $\left(m_{0}\right)$. The vial was quickly and tightly closed and weighted $\left(m_{1}\right)$ to determine the mass of sample $\left(m_{1}-m_{0}\right)$. Then the vial was covered with a piece of filter paper to prevent dust contamination. After the solvent in the vial had 
completely evaporated at room temperature, the vial was dried and reweighted $\left(m_{2}\right)$ to determine the mass of the constant residue solid $\left(m_{2}-m_{0}\right)$. All of the masses were taken using an electronic balance (Mettler Toledo AB204-S, Switzerland) with an uncertainty of $\pm 0.0001 \mathrm{~g}$. Thus, the mole fraction of the solid sample in the solution, $x$, can be determined by the following relation:

$$
x=\frac{\left(m_{2}-m_{0}\right) / M_{1}}{\left(m_{2}-m_{0}\right) M_{1}+\left(m_{1}-m_{2}\right) M_{2}}
$$

where $M_{1}$ is the molar mass of Ilaprazole and $M_{2}$ is the molar mass of solvent. At each temperature, the measurement was repeated three times and average value is given in Table 1.

\section{Acknowledgement}

Authors are thankful to Head of Chemistry department for providing necessary facilities.

Table 1: Mole fraction Solubility $(x)$ and Relative Deviation (RDs) of Ilaprazole in some alcohols.

\begin{tabular}{|c|c|c|c|c|}
\hline $\mathbf{T} / \mathbf{K}$ & $10^{3} x$ & $100 \mathrm{RD}$ & $10^{3} x$ & $100 \mathrm{RD}$ \\
\hline \multicolumn{3}{|c|}{ Methanol } & \multicolumn{2}{|c|}{ Ethanol } \\
\hline 298.15 & 0.7027 & 0.1414 & 0.4781 & 0.1404 \\
\hline 302.15 & 0.7470 & 0.0067 & 0.5146 & -0.0919 \\
\hline 306.15 & 0.7917 & -0.7428 & 0.5616 & -0.7680 \\
\hline 310.15 & 0.8508 & -0.3885 & 0.6265 & -0.9296 \\
\hline 314.15 & 0.9216 & 0.4835 & 0.7234 & 0.7292 \\
\hline 318.15 & 0.9949 & 0.7566 & 0.8341 & 0.7093 \\
\hline 322.15 & 1.0545 & -1.0551 & 0.9544 & -1.5380 \\
\hline \multicolumn{3}{|c|}{ 2-Propanol } & \multicolumn{2}{|c|}{ Butanol } \\
\hline 298.15 & 0.4736 & -0.3184 & 0.4440 & -0.4425 \\
\hline 302.15 & 0.4969 & 0.5871 & 0.4558 & 1.0245 \\
\hline 306.15 & 0.5204 & -0.8262 & 0.4625 & -1.5815 \\
\hline 310.15 & 0.5656 & -0.5448 & 0.4966 & -1.2832 \\
\hline 314.15 & 0.6318 & 0.5690 & 0.5586 & 1.0896 \\
\hline 318.15 & 0.7017 & -0.6922 & 0.6262 & 0.6202 \\
\hline 322.15 & 0.8079 & -0.0647 & 0.7070 & -1.4885 \\
\hline
\end{tabular}

Table 2: Constant A, B and C of equation (2), Relative Average Deviation (ARD) and Root meansquare Deviation (RMSD) of Ilaprazole in studied alcohols

\begin{tabular}{|c|c|c|c|c|c|}
\hline Solvent & A & B & C & RMSD & 100 ARD \\
\hline Methanol & -184.715 & 6747.558 & 27.1728 & $6.4131 \times 10^{-6}$ & -0.1140 \\
\hline Ethanol & -779.374 & 33096.89 & 115.9644 & $9.8172 \times 10^{-6}$ & -0.2498 \\
\hline 2-Propanol & -867.371 & 37740.56 & 128.6745 & $3.5486 \times 10^{-6}$ & -0.1843 \\
\hline n-Butanol & -1141.92 & 50554.66 & 169.3065 & $6.8573 \times 10^{-6}$ & -0.2940 \\
\hline
\end{tabular}

Table 3: Thermodynamic parameters, Gibbs's Energy $\left(\Delta G_{s o l}\right)$, Enthalpy $\left(\Delta H_{s o l}\right)$, and Entropy $\left(\Delta S_{s o l}\right)$, of Ilaprazole in studied alcohols.

\begin{tabular}{|c|c|c|c|}
\hline Solvent & $\frac{\Delta G}{\mathrm{~kJ} \cdot \mathrm{mol}^{-1}}$ & $\frac{\Delta H}{\mathrm{~kJ}^{-} \mathrm{mol}^{-1}}$ & $\frac{\Delta S}{\mathrm{~J}^{-1} \mathrm{~mole}^{-1} \mathrm{~K}^{-1}}$ \\
\hline Methanol & 18.20 & 13.83 & -14.69 \\
\hline Ethanol & 18.90 & 23.41 & 14.55 \\
\hline 2-propanol & 19.16 & 17.64 & -4.89 \\
\hline n-Butanol & 19.44 & 15.72 & -12.01 \\
\hline
\end{tabular}




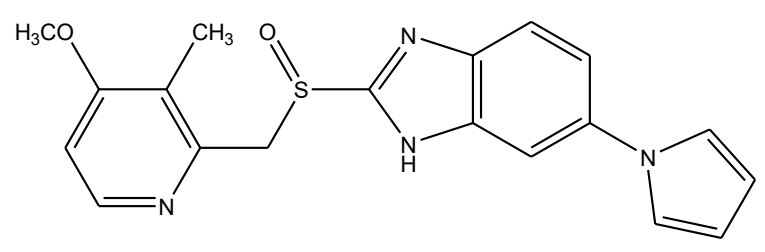

Figure 1: Chemical structure of Ilaprazole.

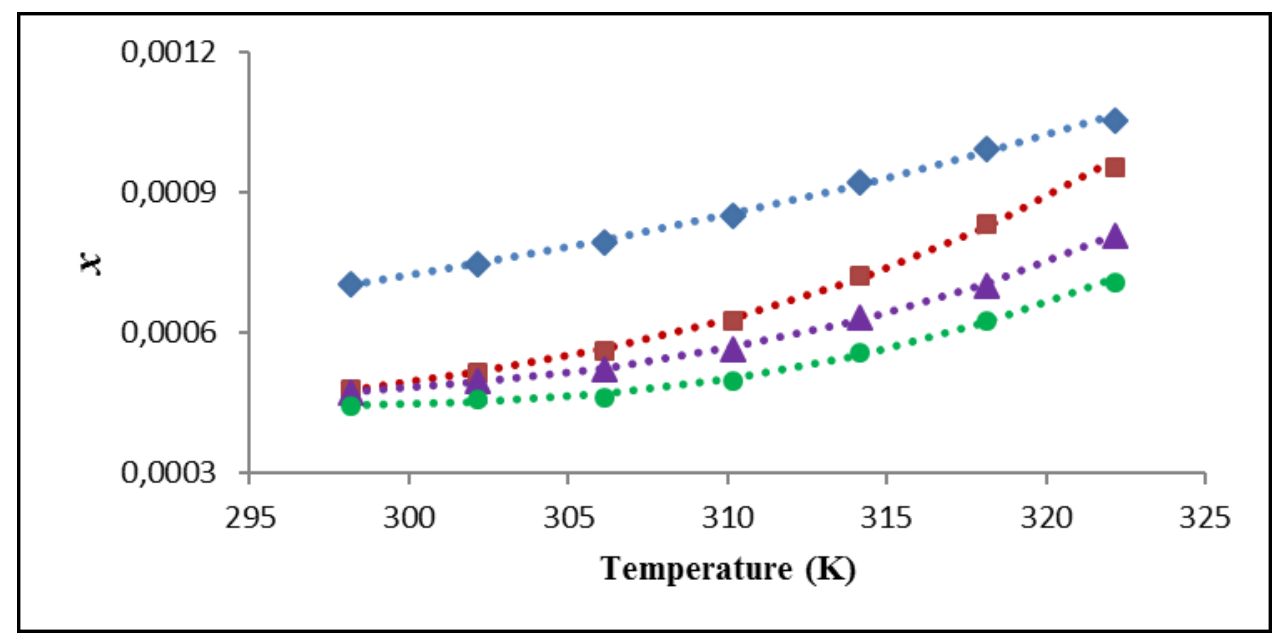

Figure 2: The variation of mole fraction solubilities $(x)$ of Ilaprazole with temperature $(T)$ in studied alcohols.

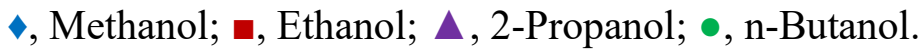

The corresponding dashed lines are for the calculated solubility values evaluated by Apelblat equation.

\section{References}

[1]. Bohinder N. P.; Krishna, K.; Panda, B. K.; Patel, C. Trop. Gastroenterol, 2013, 34(2),95-98.

[2]. De Bortoli N.; Martinucci I.; Giacchino M.; Blandizzi C.; Marchi S.; Savarino V.; Savarino E. Expert Opinion on Drug Metabolism \& Toxicology, 2013, 9(10), 1361-1369.

[3]. Wang L.; Zhou L.; Hu H.; Lin S.; Xia J. Curr. Med. Res. Opin., 2012, 28(1), 101-109.

[4]. Ji X. Q.; Du J. F.; Chen G.; Chen G.; Yu B. World J. Gastroenterol 2014, 20(17), 5119-5123.

[5]. Cao S.; Zhou G.; Yang D. O.; Wu H.; Xiao K.; Chen Y.; Guo D.; Fan L.; Tan Z.; Hu H.; Qin X.; Zhou H.; Zhang W. Acta Pharmaco. Sin. 2012, 33, 1095-1100.

[6]. Li Y.; Zhang W.; Guo D.; Zhou G.; Zhou H.; Xiao Z. Clin. Chim. Acta. 2008, 391(1-2), 60-67.

[7]. Myung S. W. ; Min H. K. ; Jin C.; Kim M.; Lee S. M. ; Chung G. J. ; Park S. J. ; Kim D.Y.; Cho H. W. Arch. Pharm. Res., 1999, 22, 189-193.

[8]. Kwon D.; Chae J. B.; Park C. W.; Kim Y. S.; Lee S. M.; Kim E. J.; Huh I. H.; Kim D. Y.; Cho K. D. Araneimittel-Forschung 2001, 51, 204-213.

[9]. Zhou G.; Tan Z. R.; Zhang W.; Ou-Yang D. S.; Chen Y.; Guo D.; Liu Y. Z.; Fan L.; Deng H. W. Acta Pharmaco. Sin. 2009, 30, 1330-1336.

[10]. Zhou G.; Shi S. Y.; Zhang W.; Tan Z. R.; Chen Y.; Guo D.; Zhou H. H.; Hu H. T.; Tan J. Biomed. Chromatogr., 2010, 24, 1130-1135.

[11]. Hao H. X.; Wang J. K.; Wang Y. L. J. Chem. Eng. Data. 2004, 49, 1697-1698.

[12]. Nie Q.; Wang J. K.; Wang Y. L. J. Chem. Eng. Data. 2005, 50, 989-992. 
[13]. Krug R. R.; Hunter W. G.; Grieger R. A. J. Phys. Chem. 1976, 80, 2341 (1976).

[14]. Kalsi, P. S. Organic reactions and their mechanisms, $2^{\text {nd }}$ edition, (New age Int. Ltd.) New Delhi, 2004.

[15]. El-Bindary A. A.; El-Sonbati A. Z.; El-Mosalamy E. H.; Ahmed R. M. Chem. Pap. 2003, 57, 255-258.

[16]. Meng Z.; Hu Y.; Kai Y.; Yang W.; Cao Z.; Shen F. Fluid Phase Equilib. 2013, 352, 1-6. 